\title{
Effect of Softening Treatment on Cutting Force during Slicing the Veneers of Common Fast-growing Wood
}

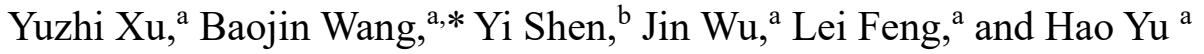 \\ To verify the effect of softening treatment on the cutting force during slicing \\ of veneers, an experiment was performed using a veneer slicer with steam \\ injection heating function. Several conditions were set to soften the \\ experimental materials of poplar (Populus L.), eucalyptus (Eucalyptus \\ robusta Smith), pine (Pinus massoniana Lamb.), and Chinese fir \\ (Cunninghamia lanceolata (Lamb.) Hook.). The cutting force was detected \\ by the YE7600 signal analysis system. The results showed that the cutting \\ force increased with increased slicing thickness. The cutting force was \\ observed to follow the order, from high to low for the conditions of being \\ soaked in cold water, then steam heated, water-poached, and steam heated \\ again. Compared to the case of non-steam heating, the effect of steam \\ heating on reducing the cutting force was satisfactory, and the maximum \\ decrease percentage reached $83.1 \%$. The cutting force was positively \\ related to the wood density and hardness, and the cutting stroke had a great \\ influence on the cutting force. After being softened, the four kinds of fast- \\ growing wood were sliced into veneers with $\leq 6 \mathrm{~mm}$ thickness, and the \\ cutting force was generally no more than $6850 \mathrm{~N}$.
}

Keywords: Slicing; Fast-growing wood; Softening treatment; Cutting force

Contact information: a: Faculty of Material Science and Engineering, Nanjing Forestry University, Nanjing 210037, China; b: Zhenjiang Zhongfuma Machinery Co., Ltd., Zhenjiang 212016, China; *Corresponding author:wangbaojincn@139.com.cn

\section{INTRODUCTION}

With the increasing shortage of forest resources, the contradiction between supply and demand has become prominent worldwide. Therefore, amount of veneer-overlaying technology is rising. The key to this technology is sticking a sandwich of wood veneer on the surface of a wood-based panel so that the panel does not look significantly different from solid wood ( $\mathrm{Li}$ 1998). Veneers can be obtained by sawing or slicing. The latter belongs to chipless cutting and has a high timber utilization rate. For these reasons, it has been widely used to manufacture veneers. However, deeper cracks tend to appear on the back of thick veneers (if the thickness is more than $2 \mathrm{~mm}$ ) sliced by the existing veneer slicer (Li et al. 2010), and this will seriously affect the subsequent processes.

To reduce the back cracks, softening treatment is necessary to increase the wood plasticity. In addition, softening treatment can reduce the cutting resistance, decrease the equipment energy consumption and reduce the tool wear. Therefore, it has practical significance in improving product quality and reducing production cost.

In the practical production, a water-poaching method is often used to soften the wood material, but the treated result is still unsatisfactory. Therefore, scholars have tried using a heating-cutting technology to slice veneer and improve the cutting quality. 
Walser (1975) directed a heated fluid into the cutting region to raise the temperatures of the blade and cutting region during veneer rotary cutting. Thereafter, the pressure bar was also heated to reduce the frictional drag against the wood surface (McLauchlan and Walser 1980). The results showed that the cutting force, surface roughness, and tool wear decreased, which could offer a reference for slicing processing with steam injection heating.

Zeng and Wang (2001) came up with a new method for reducing the surface roughness of veneer, which involved steam heating the soaked wood a short time during the cycle of a veneer slicing to make wood expanded and softened. The results showed that the surface smoothness of veneers was increased by $20 \%$ to $30 \%$.

Dundar et al. (2008) studied the effects of veneer thickness, knife bevel, vertical, and horizontal opening on the surface roughness on sliced Makore veneer and rotary-cut beech veneer. They concluded that surface roughness increased with the increasing veneer thickness. The most suitable knife bevel was $17.51^{\circ}$ for manufacturing sliced Makore veneers, and the vertical and horizontal opening had a significant effect on the surface roughness of rotary-cut veneers.

Olufemi (2012) investigated the yield and tensile strength of sliced veneers and rotary-cut veneers produced from Brachystegia nigerica, and the optimum condition for veneer production was obtained via controlling the steam temperature and action time. Liu (2015) conducted an experiment on rotary-cut elm after water-poaching. The conclusions were as follows: with the increase of the water temperature and the veneer thickness, the hardness of the wood gradually decreased, and the surface roughness of the veneer decreased. Under the conditions set in this study, the optimum softening temperature was $100{ }^{\circ} \mathrm{C}$ and the softening time was $8 \mathrm{~h}$.

In summary, most scholars have judged the cutting quality by studying the influences of various factors on the surface roughness of veneers. In addition to the surface roughness, cutting force is an important index, which has directly effect on cutting quality in practice (Zhou 2004).

Therefore, in this experiment, the cutting quality was verified by measuring the cutting force in the slicing process. The veneer slicer with real-time steam injection heating function was used, and the wood samples were pretreated by four kinds of softening conditions, namely being soaked in cold water, steam heating after soaking in cold water, water-poaching, and steam heating after water-poaching. The YE7600 signal acquisition and analysis system was used to detect the change of cutting force during the slicing process; then the softening effects under different conditions and the comparison of cutting forces from different tree species could be tested. In addition, the cutting force ranges of slicing wood after softening treatment were obtained, which can provide a reference for slicing equipment selection.

\section{EXPERIMENTAL}

\section{Materials}

Several common fast-growing woods were chosen as the experimental raw materials, poplar, eucalyptus, pine, and Chinese fir. Their main physical and mechanical properties are shown in Table 1 (Cheng 1992). Each was machined into some flitches. 
Table 2 provides an overview of these samples. In this experiment, four kinds of softening conditions were set to pretreat the flitches. The first condition was recorded as being soaked in cold water, and flitches were sliced after being soaked in cold water for some time (Table 2) under this condition. The second condition was recorded as being steam heated after being soaked in cold water; the soaked flitches were sliced via real-time steam injection heating under this condition. The third condition was water-poaching, and flitches were sliced after being poached in a thermostatic water container at $60{ }^{\circ} \mathrm{C}$ under this condition. The fourth one was recorded as being steam heated after water-poaching, and the poached flitches were sliced via real-time steam injection heating under this condition. The cold-water temperature corresponded to the air temperature of this experimental site, where the mean temperature was $5{ }^{\circ} \mathrm{C}$ to $14{ }^{\circ} \mathrm{C}$. The saturated vapor pressure was $0.4 \mathrm{MPa}$ when the veneers were sliced via real-time steam injection heating. In addition, appropriate soaking and poaching time were selected according to the properties and moisture contents of these woods (Table 2).

Table 1. The Main Physical and Mechanical Properties of Wood

\begin{tabular}{|c|c|c|c|c|}
\hline \multirow{2}{*}{ Tree Species } & \multirow{2}{*}{$\begin{array}{c}\text { Air-dry Density } \\
\left(\mathrm{g} / \mathrm{cm}^{3}\right)\end{array}$} & End Section & Radial Section & Tangential Section \\
\cline { 3 - 5 } & 0.454 & 31.9 & 23.1 & 23.3 \\
\hline Poplar & 0.604 & 54.9 & 38.4 & 41.0 \\
\hline Eucalyptus & 0.533 & 42.2 & 32.2 & 36.0 \\
\hline Pine & 0.355 & 28.6 & 12.8 & 15.4 \\
\hline Chinese fir & \multicolumn{4}{|c|}{} \\
\hline * This air dry density referred to the density of wood with 15\% moisture content \\
\hline
\end{tabular}

Table 2. Properties and Softening Time of the Fitches

\begin{tabular}{|c|c|c|c|c|c|c|}
\hline $\begin{array}{c}\text { Tree } \\
\text { Species }\end{array}$ & $\begin{array}{c}\text { Diameter } \\
(\mathrm{mm})\end{array}$ & $\begin{array}{c}\text { Producing } \\
\text { Area }\end{array}$ & $\begin{array}{c}\text { Moisture } \\
\text { Content }(\%)\end{array}$ & $\begin{array}{c}\text { Size } \\
\left(\mathrm{mm}^{*} \mathrm{~mm}^{*} \mathrm{~mm}\right)\end{array}$ & $\begin{array}{c}\text { Soaking } \\
\text { Time (day) }\end{array}$ & $\begin{array}{c}\text { Poaching } \\
\text { Time (day) }\end{array}$ \\
\hline Poplar & 300 & $\begin{array}{c}\text { Jiangsu } \\
\text { China }\end{array}$ & 110 to 125 & $250^{*} 160^{*} 160$ & 3 & 3 \\
\hline Eucalyptus & 220 & Australia & 105 to 135 & $240^{*} 160^{*} 160$ & 14 & 7 \\
\hline Pine & 200 & $\begin{array}{c}\text { Zhejiang } \\
\text { China }\end{array}$ & 100 to 120 & $240^{*} 130^{*} 130$ & 7 & 7 \\
\hline Chinese fir & 200 & $\begin{array}{c}\text { Zhejiang } \\
\text { China }\end{array}$ & 75 to 90 & $240 * 130^{*} 130$ & 7 & 7 \\
\hline
\end{tabular}

\section{Equipment}

This veneer slicer was designed independently; its outline drawing is shown in Fig. 1. The stander (2) is the support of the whole device. The vertical feed mechanism (1) drives the flitch to feed up and down along vertical direction. The hydraulic cylinder (3) provides the cutting power for the whole slicing device, and drives the slicing mechanism (4) to slice horizontally. 


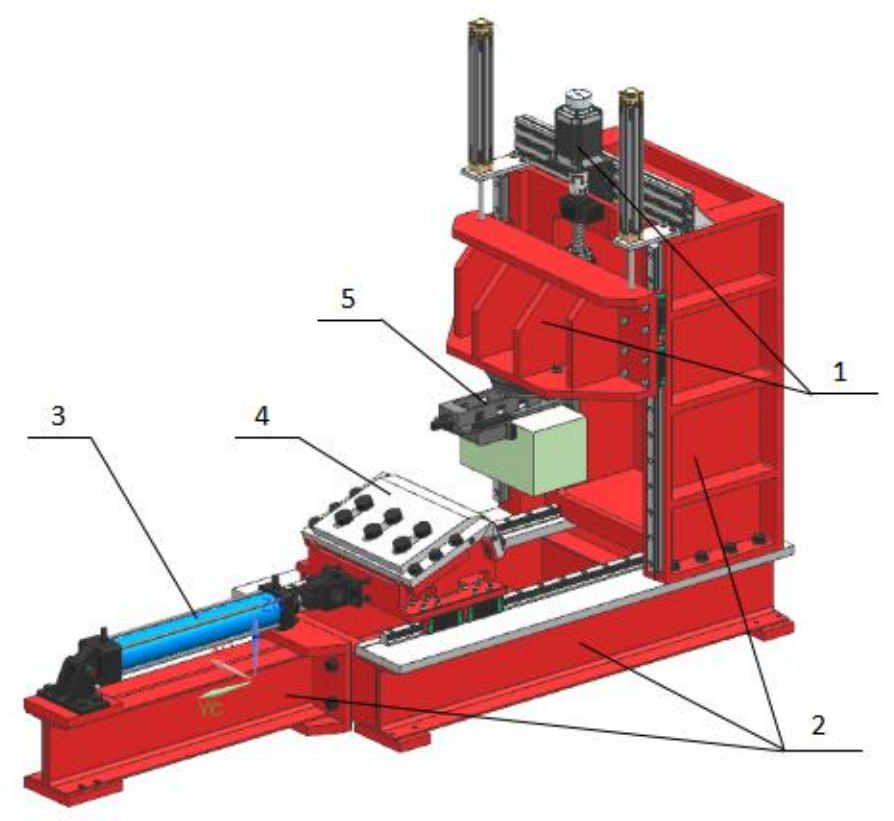

Fig. 1. The outline of the veneer slicer; 1-Vertical feed mechanism; 2-Stander; 3-Hydraulic cylinder; 4Slicing mechanism; and 5-Flitch clamping mechanism

The feed mechanism drives the flitch to fall a certain height after a veneer slicing; the height is equal to the thickness of the next veneer (Xu et al. 2014). Two steam passages were laid in the slicer tool plate and the pressure bar plate, respectively (Fig. 3). One end of the passage was connected with the steam generator, with the other end transporting steam to heat and soften the flitch during the slicing process. The flitch clamping mechanism (5) can be rotated in a horizontal plane to adjust the tool cutting edge inclination angle, so that the tool can cut-in slowly, and the impact can be reduced. A force sensor was installed between the front lug of the hydraulic cylinder and the slicing mechanism. A force analysis diagram of the slicing process is shown in Fig. 2.

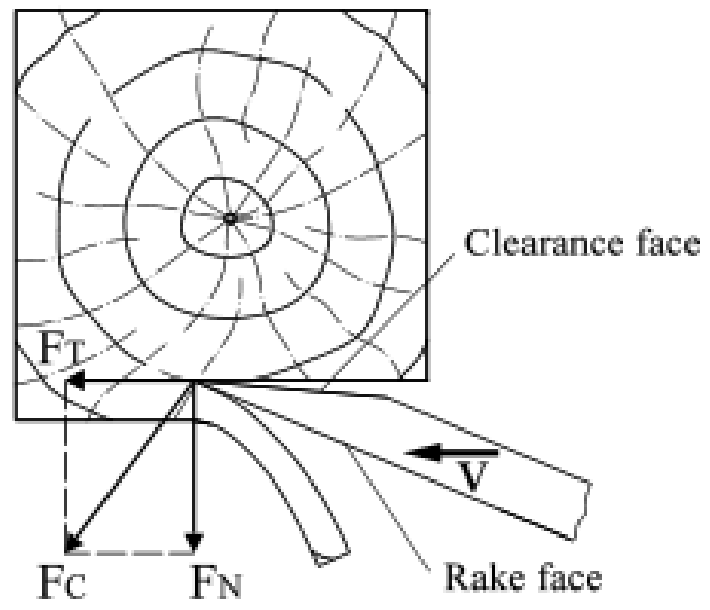

Fig. 2. Force analysis diagram of slicing process 
The resultant cutting force $F_{C}$ was decomposed into horizontal component $F_{T}$ and vertical component $F_{N}$ (Aknouche et al. 2008); $F_{T}$ was derived from the cutting power provided by the cylinder, and was consistent with the direction of the slicing feed. To ensure the accuracy and convenience of measurement, $F_{T}$ was measured and as the cutting force in this experiment.

The signal analysis system (model number YE7600, Sinocera Piezotronics Inc., Yangzhou, China) was used to measure the cutting force in this experiment. The system hardware consists of a piezoelectric force sensor (model number CL-YD-305, Sinocera Piezotronics Inc., Yangzhou, China), a charge amplifier (model number YE5850B, Sinocera Piezotronics Inc., Yangzhou, China), a dynamic data acquisition (model number YE6231, Sinocera Piezotronics Inc., Yangzhou, China), and a computer.

\section{Methods}

A veneer slicer was used to perform the experiment with a steam injection heating function. The system was designed by Nanjing Forestry University (Nanjing, China) and was made by Jiangjia Machinery Co., Ltd. (Dongtai, China). It takes less time to slice flitches transversely than to slice longitudinally, but veneers are more prone to lacerations and other defects due to the greater tensile stress in the process of transversely slicing (Pfriem and Buchelt 2011). Thus, it makes more sense to study the transverse slicing technique for improving the efficiency of slicing veneers. The specimen was installed directionally to make the cutting direction perpendicular to the wood fibers direction, i.e. transversely slicing. In this experiment, the slicing speed was $2.5 \mathrm{~mm} / \mathrm{min}$. The compression of pressure bar was $10 \%$, the wedge angle of the tool was $18^{\circ}$, the wedge angle of the pressure bar was $30^{\circ}$, and the tool cutting edge inclination angle was $5^{\circ}$. The flitches after the softening treatment were sliced into veneers with the thickness of $1 \mathrm{~mm}$, $2 \mathrm{~mm}, 3 \mathrm{~mm}, 4 \mathrm{~mm}, 5 \mathrm{~mm}$, and $6 \mathrm{~mm}$. They were sliced repeatedly to obtain three veneers of each thickness specification. The measurement and evaluation began with the second sliced veneer for reducing the errors. The tool was ground using a whetstone before each slicing to make sure of the slicing quality. The YE7600 signal analysis system was used to measure and record the cutting force, its sketch map is shown in Fig. 3.

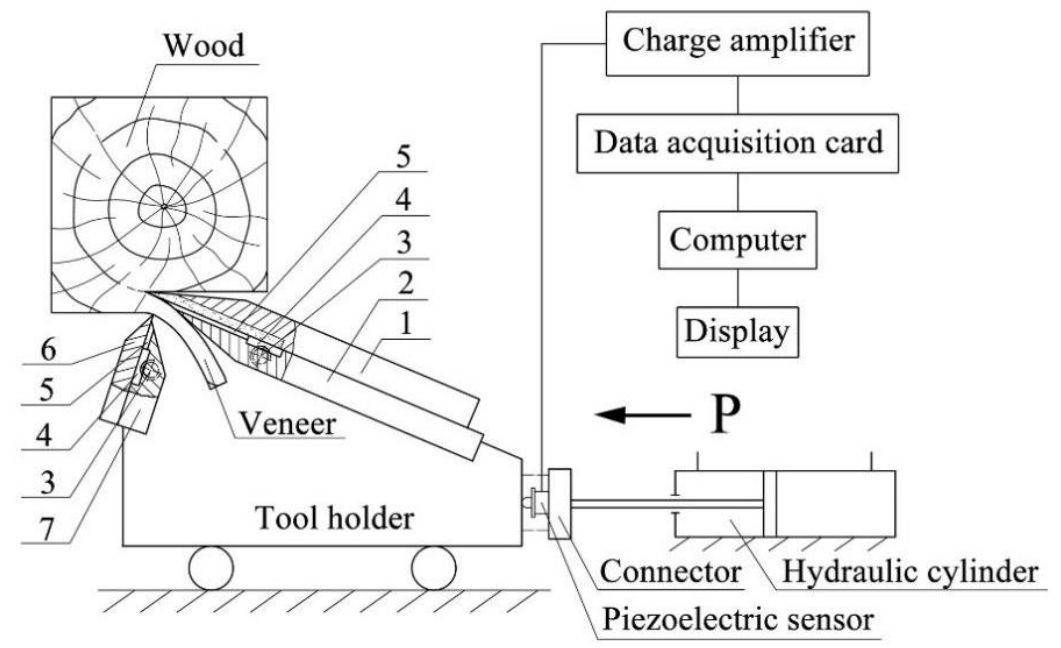

Fig. 3. Sketch map of the signal analysis system; 1-Slicer tool; 2-Tool plate; 3-Steam joint; 4-Steam passage; 5-Steam jet; 6-Pressure bar; and 7-Pressure bar plate 
The piezoelectric sensor was installed between the tool holder and the hydraulic cylinder. The wood was then sliced by the tool with the driving of the hydraulic cylinder. The piezoelectric sensor was negative electrical charge under pressure $P$. This pressure represented the cutting force in the slicing process. Negative charges were transferred to the charge amplifier and were then amplified, converted into analog voltage signals, and outputted. The analog signals were converted into digital signals by the data acquisition card and were collected in a computer. Then, the data were analyzed, displayed, and recorded by YE7600 signal analysis software (Sinocera Piezotronics Inc., V5.8, Yangzhou, China) (Wu et al. 2004).

\section{RESULTS AND DISCUSSION}

To reduce the impact force during slicing, the slicer tool gradually cut into and cut out from the wood due to the presence of an edge inclination angle, which made the slicing process more stable and the cutting quality guaranteed. With this cutting method, the curve pattern showed that the cutting force along with the time increased at first, then remained stable, and decreased later on (Fig. 4); the cutting force data from the stable time period was taken and analyzed. The apparent maximum at about 11.6 seconds indicated the critical point at which the tool had completely cut into the material. At about $11.1 \mathrm{~s}$, the sharp edge entered the material, so the curve suddenly rose. Analogously, at about $15.1 \mathrm{~s}$, the tool completely cut out from the material, so the curve suddenly declined.

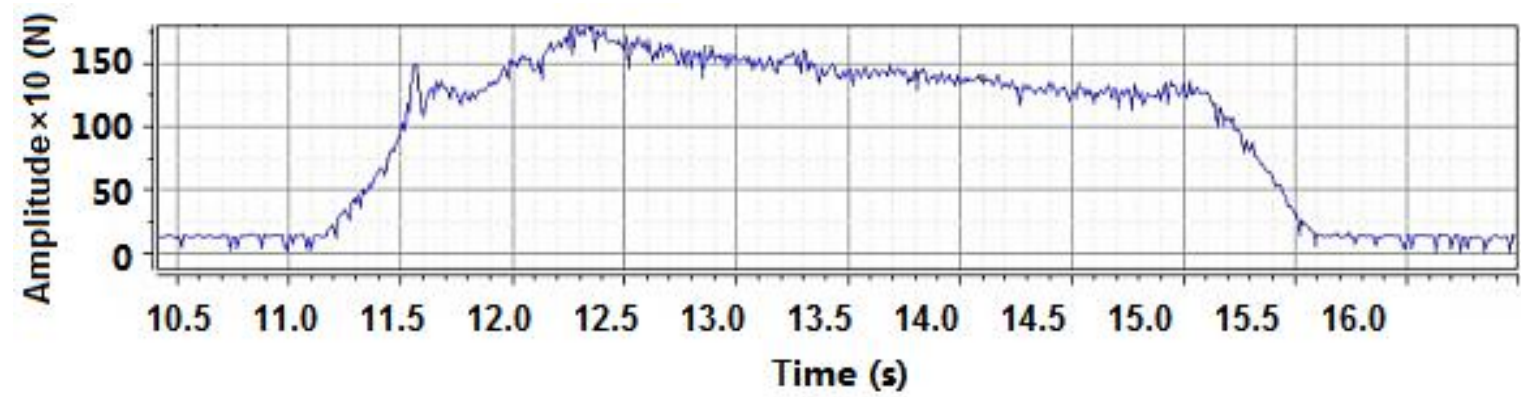

Fig. 4. Variation of cutting force along with time in the process of slicing

The cutting force data were obtained from the time domain waveform and exported by the supporting software, the average value of these data was recorded as the cutting force for slicing this veneer. Then, the three sets of cutting force values measured from repeated slicing were averaged, and the mean value was regarded as the cutting force for this type of sliced veneer, the results are shown in Table 3.

The cutting force decrease percentage was calculated according to Eq. 1,

Decrease Percentage $(\%)=[(B-A) / A] * 100$

where $A$ represents the cutting force of sliced veneers under the condition of being soaked in cold water, and $B$ represents the cutting force of sliced veneers under the condition of being steam heated after being soaked in cold water. This also applied to the case of being water-poached and being steam heated after being water-poached. The results are shown in Table 4. Negative values indicate that the cutting force was not reduces. 
Table 3. The Cutting Force data of Sliced Veneers

\begin{tabular}{|c|c|c|c|c|c|}
\hline \multirow[b]{2}{*}{$\begin{array}{c}\text { Tree } \\
\text { Species }\end{array}$} & \multirow[b]{2}{*}{$\begin{array}{c}\text { Slicing } \\
\text { Thickness } \\
(\mathrm{mm})\end{array}$} & \multicolumn{4}{|c|}{ Cutting Force Data under Different Softening Conditions (N) } \\
\hline & & $\begin{array}{l}\text { Soaking in } \\
\text { Cold Water }\end{array}$ & $\begin{array}{c}\text { Steam Heating After } \\
\text { Soaking in Cold } \\
\text { Water }\end{array}$ & Water-poaching & $\begin{array}{l}\text { Steam Heating } \\
\text { After Water- } \\
\text { poaching }\end{array}$ \\
\hline \multirow{6}{*}{ Poplar } & 1 & 1430.3 & 1184.8 & 1091.4 & 650.9 \\
\hline & 2 & 3216.2 & 2807.4 & 1501.5 & 1231.9 \\
\hline & 3 & 3246.6 & 3021.0 & 2763.3 & 2572.8 \\
\hline & 4 & 3878.1 & 3611.3 & 2643.2 & 2495.7 \\
\hline & 5 & 4008.8 & 3795.0 & 4867.0 & 2979.4 \\
\hline & 6 & 6845.7 & 6293.9 & 5244.9 & 3572.9 \\
\hline \multirow{6}{*}{ Eucalyptus } & 1 & 1243.7 & 1228.1 & 902.0 & 769.6 \\
\hline & 2 & 2089.3 & 1712.4 & 1638.4 & 1653.2 \\
\hline & 3 & 2631.6 & 2543.5 & 2411.1 & 2146.1 \\
\hline & 4 & 2865.9 & 2639.6 & 2730.7 & 2204.4 \\
\hline & 5 & 3158.5 & 3012.8 & 2759.2 & 2768.9 \\
\hline & 6 & 4046.3 & 3576.3 & 3671.1 & 3628.3 \\
\hline \multirow{6}{*}{ Pine } & 1 & 1610.8 & 1046.7 & 1128.4 & 831.9 \\
\hline & 2 & 1962.8 & 1911.2 & 1667.4 & 1471.4 \\
\hline & 3 & 2194.6 & 1892.4 & 1907.3 & 1837.3 \\
\hline & 4 & 2621.9 & 2870.5 & 2394.2 & 1912.8 \\
\hline & 5 & 3097.9 & 2951.3 & 2725.3 & 2507.1 \\
\hline & 6 & 3563.9 & 3415.7 & 2374.6 & 1892.4 \\
\hline \multirow{6}{*}{ Chinese fir } & 1 & 799.8 & 734.7 & 786.2 & 133.0 \\
\hline & 2 & 1331.4 & 1387.1 & 1136.5 & 306.9 \\
\hline & 3 & 1558.2 & 1392.0 & 1076.0 & 743.6 \\
\hline & 4 & 1960.3 & 1566.5 & 1392.9 & 1257.2 \\
\hline & 5 & 2842.2 & 2083.2 & 1528.3 & 1763.0 \\
\hline & 6 & 2532.5 & 1918.2 & 2434.4 & 2375.2 \\
\hline
\end{tabular}

\section{Comparison of Cutting Force under Different Softening Conditions}

The cutting force line charts of different softening conditions (Fig. 5) were drawn according to the experimental data from Table 4, to compare the influences of the different softening conditions on the cutting force. With increasing of cutting thickness, the cutting resistance also increased, and thus the cutting force showed an increased tendency. For the same tree species, the cutting force was smallest under the condition of steam heating after water-poaching, followed by being water-poached, being steam heated after being soaked in cold water, and being soaked in cold water (Fig. 5). Different softening mechanisms yielded different results. After being soaked in cold water, the wood expanded and the internal force was weakened; thus the wood plasticity increased. After being waterpoached, on this basis, the non-crystalline region of cellulose expanded, the lignin presented a viscous state, and the hemicellulose lost the interconnect function, thus the wood plasticity further increased. The hot steam could soften the cutting zone quickly during slicing. The softening effect of real-time steam heating was not as good as waterpoaching, but the softening time was decreased remarkably. Most of the decrease 
percentage values were positive (Table 4). This meant that the steam heating treatment method reduced the cutting force in the process of slicing veneers, especially in cooperation with the water-poaching method.

Table 4. The Cutting Force Decrease Percentage of Sliced Veneers under Different Softening Conditions

\begin{tabular}{|c|c|c|c|}
\hline \multirow{2}{*}{$\begin{array}{c}\text { Tree } \\
\text { Species }\end{array}$} & \multirow{2}{*}{$\begin{array}{c}\text { Slicing } \\
\text { Thickness (mm) }\end{array}$} & \multicolumn{2}{|c|}{ Cutting Force Decrease Percentage (\%) } \\
\hline & & $\begin{array}{c}\text { Steam Heating After Soaking in } \\
\text { Cold Water }\end{array}$ & $\begin{array}{l}\text { Steam Heating After Water- } \\
\text { poaching }\end{array}$ \\
\hline \multirow{6}{*}{ Poplar } & 1 & 17.16 & 40.36 \\
\hline & 2 & 12.71 & 17.96 \\
\hline & 3 & 6.95 & 6.89 \\
\hline & 4 & 6.88 & 5.58 \\
\hline & 5 & 5.33 & 38.78 \\
\hline & 6 & 8.06 & 31.88 \\
\hline \multirow{6}{*}{ Eucalyptus } & 1 & 1.25 & 14.68 \\
\hline & 2 & 18.04 & -0.90 \\
\hline & 3 & 3.35 & 10.99 \\
\hline & 4 & 7.90 & 19.27 \\
\hline & 5 & 4.61 & -0.35 \\
\hline & 6 & 11.62 & 1.17 \\
\hline \multirow{6}{*}{ Pine } & 1 & 35.02 & 26.28 \\
\hline & 2 & 2.63 & 11.75 \\
\hline & 3 & 13.77 & 3.67 \\
\hline & 4 & -9.48 & 20.11 \\
\hline & 5 & 4.73 & 8.01 \\
\hline & 6 & 4.16 & 20.31 \\
\hline \multirow{6}{*}{ Chinese fir } & 1 & 8.14 & 83.08 \\
\hline & 2 & -4.18 & 73.00 \\
\hline & 3 & 10.67 & 30.89 \\
\hline & 4 & 20.09 & 9.74 \\
\hline & 5 & 26.70 & -15.36 \\
\hline & 6 & 24.26 & 2.43 \\
\hline
\end{tabular}

As shown in Table 4, compared to the case of non-steam heating, the maximum cutting force decrease percentage of slicing poplar veneers was $40.36 \%$ with the slicing thickness of $1 \mathrm{~mm}$; for eucalyptus the maximum decrease percentage was $19.27 \%$ with the slicing thickness of $4 \mathrm{~mm}$; for pine the maximum decrease percentage was $35.02 \%$ with the slicing thickness of $1 \mathrm{~mm}$; for Chinese fir the maximum decrease percentage was $83.08 \%$ with the slicing thickness of $1 \mathrm{~mm}$. In addition, when the common fast-growing wood, after the softening treatment, was sliced into veneers with $\leq 6 \mathrm{~mm}$ thickness, the cutting force data were generally not more than $6850 \mathrm{~N}$ (Table 3). The cutting forces for slicing veneers with other thickness specifications can be extrapolated from the experimental data. 
This provides a theoretical basis for the power selection, structural design, and check calculation of a veneer slicer (Ma and He 2015).

Figure 5a shows that for poplar slicing, when the slicing thickness was $1 \mathrm{~mm}$ to 4 $\mathrm{mm}$, the effect of the steam heating treatment on reducing the cutting force was not obvious. However, when the slicing thickness was $4 \mathrm{~mm}$ to $6 \mathrm{~mm}$, under the condition of being steam heated after being water-poached, the cutting force was clearly lower than the other conditions, and the softening effect was stable and desirable. In addition, under the condition of water-poaching, the cutting force increased considerably as the cutting thickness was $5 \mathrm{~mm}$, because the knot hidden inside the poplar was cut at this time.
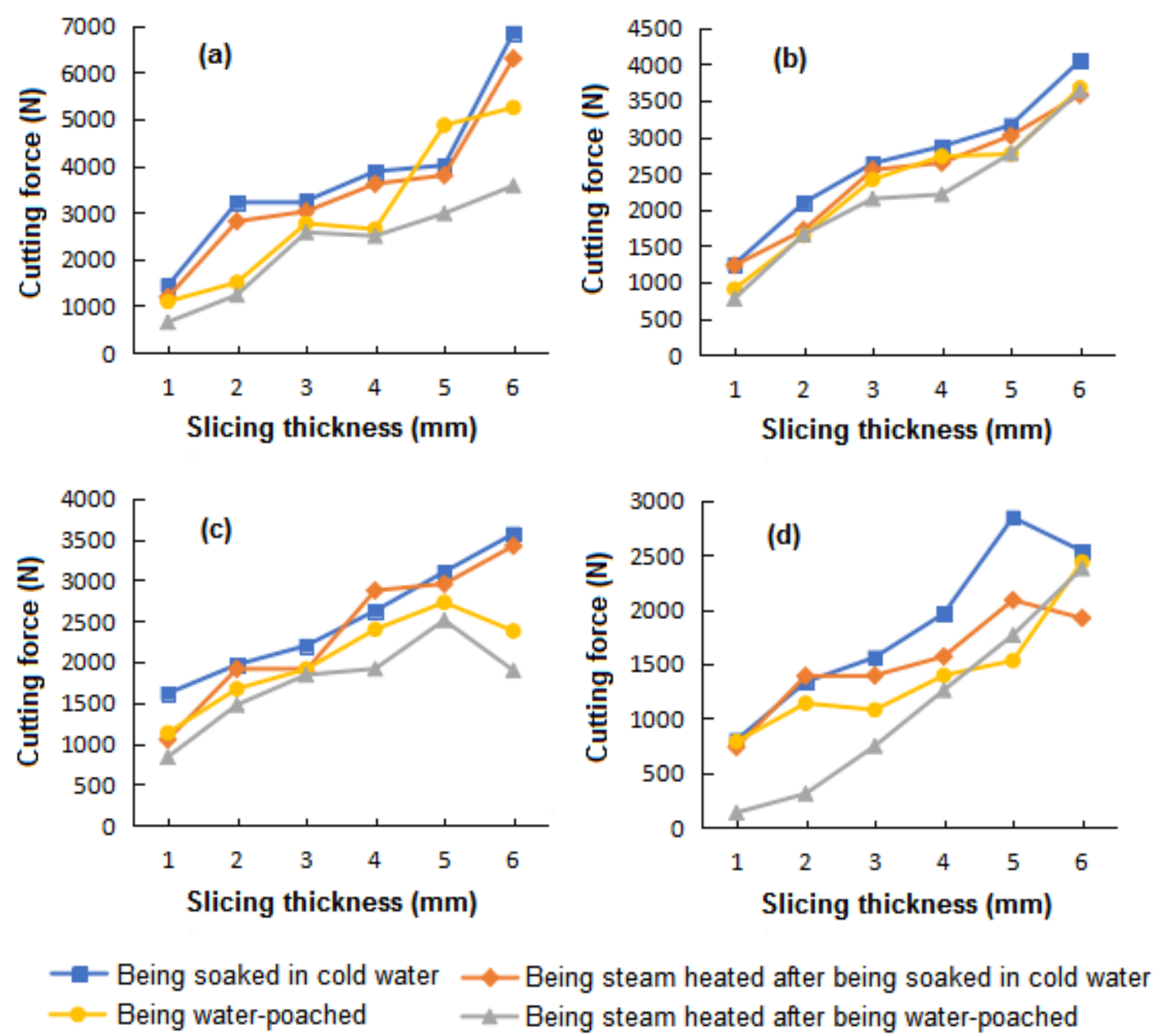

Fig. 5. The cutting force line charts under different softening conditions; a) Poplar, b) Eucalyptus, c) Pine, and d) Chinese fir

For eucalyptus slicing (Fig. 5b), the four curves were all raised at a large rate, which showed that the veneer thickness had a great effect on the cutting force. The spaces between each line were not too large, which indicated that the wood property had a great influence on cutting force of slicing eucalyptus and other wood with larger hardness values. For slicing pine (Fig. 5c), the water-poaching curve and the soaking in cold water curve 
maintained stable spacing, which indicated that the softening effect of hot water was better than cold water. Moreover, the steam heating after water-poaching curve was the lowest, so this softening method was used to minimize the cutting force during the slicing of pine veneers. For slicing Chinese fir (Fig. 5d), when the slicing thickness was $1 \mathrm{~mm}$ to $4 \mathrm{~mm}$, the effect of steam heating on reducing the cutting force was positive, while when the slicing thickness was $4 \mathrm{~mm}$ to $6 \mathrm{~mm}$, the advantage of the water-poaching treatment method was reflected. When the fir veneers with the thickness of $6 \mathrm{~mm}$ were sliced under the two kinds of soaking in cold water conditions, the cutting force was suddenly and greatly reduced, which was because some part of the fir veneers were cataclysmic during slicing.

\section{Comparison of Cutting Force between Different Tree Species}

In addition, in order to explore the change regularities of cutting force between different tree species in the slicing process, the cutting force line charts of different tree species (Fig. 6) were drawn.
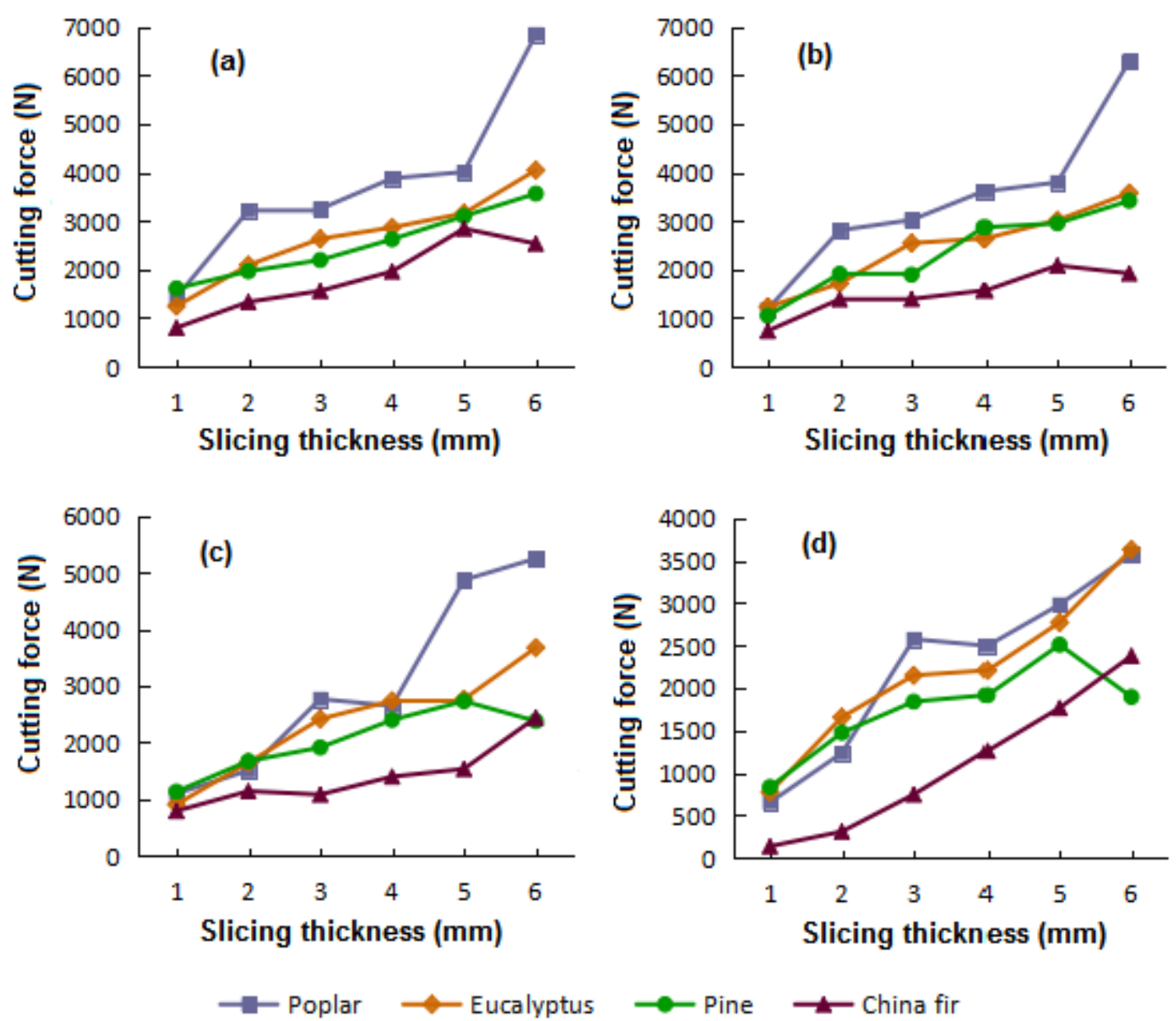

Fig. 6. The cutting force line charts of different tree species; a) Being soaked in cold water, b) Being steam heated, c) Being water-poached, and d) Being steam heated after being waterpoached 
The cutting force from high to low in turn was slicing poplar, then slicing eucalyptus, pine, and Chinese fir, Different wood properties yielded different results. As shown in Table 1, The Chinese fir had a small density and soft material, so its cutting force was the smallest. The eucalyptus had the highest density and hardness, and thus the cutting force was relatively large. Because of the presence of turpentine, the wettability of pine was relatively poor, and the plasticity of pine increased little after being softened relative to other woods. Also, the turpentine increased the cutting resistance, so although the density and hardness of pine was lower than those of eucalyptus, the cutting forces of the two were similar. Fig. $6 \mathrm{~d}$ showed that, the softening method of steam heating after waterpoaching was more suitable for the pine, which contained more resin. The material of poplar was soft, the density and intensity were small (Chai et al. 2016). But the length of the poplar specimen was longer than the other species, the contact area during slicing was larger than the other specimens, and thus the cutting resistance increased and the cutting force data measured was also larger.

\section{CONCLUSIONS}

1. An increase in the slicing thickness resulted in an increased trend in the cutting force in the slicing process.

2. Because of the different softening mechanisms, the cutting force ranged from high to low in the order of conditions as follows: being soaked in cold water, then steam heated, water-poached, and steam heated again. Compared to the case of non-steam heating, the effect of steam heating on reducing the cutting force was satisfactory, and the maximum decrease percentage reached $83.08 \%$.

3. Because of the different wood properties, the cutting force ranged from high to low for slicing poplar, then slicing eucalyptus, pine, and Chinese fir, which indicated that the cutting force was positively related to the density and hardness of wood, and the cutting stroke had a great influence on the cutting force.

4. When these common fast-growing wood samples were sliced into veneers with $\leqslant$ $6 \mathrm{~mm}$ thickness, after the softening treatment, the cutting force values were generally not more than $6850 \mathrm{~N}$.

\section{ACKNOWLEDGMENTS}

This study was funded by the "12th Five-Year" National Science and Technology Support Program (2012BAD24B010202), and the Priority Academic Program Development of Jiangsu Higher Education Institutions (PAPD). 


\section{REFERENCES CITED}

Aknouche, H., Outahyon, A., Nouveau, C., Marchal, R., Zerizer, A., and Butaud, J. (2008). "Tool wear effect on cutting forces: In routing process of Aleppo pine wood," Journal of Materials Processing Technology 209(6), 2918-2922. DOI: 10.1016/j.jmatprotec.2008.06.062

Chai, Y., Liu, J., and Wang, F. (2016). "Effect of different modification methods on the fixation of compression and properties of plantation poplar wood," Wood Processing Machinery 27(5), 16-19. DOI: 10.13594/j.cnki.mcjgjx.2016.05.005

Cheng, J. (1992). "Chinese wood Annals," China Forestry Publishing House press, Beijing, China.

Dundar, T., Akbulut, T., and Korkut, S. (2008). "The effects of some manufacturing factors on surface roughness of sliced Makoré (Tieghemella heckelii, Pierre Ex A. Chev.) and rotary-cut beech (Fagus orientalis, L.) veneers," Building and Environment 43(4), 469-474. DOI: 10.1016/j. Buildenv. 2007. 01. 002

Li, D. (1998). "Veneer overlaying and planer," Woodworking Machinery 20(1), 16-21.

Li, W., Cao, P., Wang, B., Guo, X., and Ding, J. (2010). "Forming and influencing factors of veneer back clearance during longitudinal slicing," China Wood Industry 24(2), 810. DOI: 10.3969/j.issn.1001-8654.2010.02.003

Liu, R. (2015). Study on Effect of Hydrothermal Treatment on Elm Mechanical Properties and Surface Roughness of Peeling Microveneer, Master's Thesis, Inner Mongolia Agricultural University, Inner Mongolia, China.

Ma, Y., and He, H. (2015). "The cutting principle and mechanical analysis of a longitudinal slicing machine," Wood Processing Machinery 26(5), 5-7. DOI: 10.13594/j.cnki.mcjgjx.2015.05.002

McLauchlan, T., and Walser, D. (1980). "Pressure bar for veneer cutting," U. S. Patent No. 4222421 A.

Olufemi, B. (2012). "Yield and mechanical properties of veneer from Brachystegia nigerica," Journal of Forestry Research 23(2), 295-298. DOI: 10.1007/s11676-0120255-3

Pfriem, A., and Buchelt, B. (2011). "Influence of the slicing technique on mechanical properties of the produced veneer," European Journal of Wood and Wood Products 69(1), 93-99. DOI: 10.1007/s00107-010-0410-5

Walser, D. (1975). "Veneer peeling with fluid injection,” U. S. Patent No. 3866642.

Wu, G., Chen, S., and Li, M. (2004). "Transforming and design of a wood-cutting force testing system," Wood Processing Machinery 15(6), 25-27. DOI: 10.13594/j.cnki.mcjgjx.2004.06.008

$\mathrm{Xu}$, W., Song, X., Sun, Y., and Yu, Y. (2014). "The structure and use of slicer," China Wood-Based Panels 21(7), 23-28. DOI: 10.3969/j.issn.1673-5064.2014.07.009

Zeng, C., and Wang, Q. (2001). "Effects of heating flitches for short time on surface 
roughness of sliced veneers," Building Artificial Boards 14(1), 8-10.

Zhou, M. (2004). Study on Cutting Force and Quality of the Sliced Veneer used in Laminated Veneer Lumber, Master's Thesis, Northeast Forestry University, Harbin, China.

Article submitted: April 17, 2017; Peer review completed: August 6, 2017; Revised version received: August 9, 2017; Accepted: August 10, 2017; Published: August 16, 2017.

DOI: $10.15376 /$ biores. 12.4.7205-7217 